\title{
Practitioners' views on managing childhood obesity in primary care: a qualitative study
}

\author{
Katrina M Turner, Julian PH Shield and Chris Salisbury
}

\begin{abstract}
\section{Background}

In 2006 the Department of Health and the National Institute for Health and Clinical Excellence (NICE) published guidance on the management of childhood obesity, for use by primary care practitioners. Little is known, however, about practitioners' views and experiences of managing childhood obesity in primary care.
\end{abstract}

Aim

To explore practitioners' views of primary care as a setting in which to treat childhood obesity.

Design of study

Qualitative interview study.

Setting

Primary care and other community settings based in Bristol, England.

Method

Interviews explored practitioners' views and experiences of managing childhood obesity and their knowledge of the recent guidance provided by the Department of Health and NICE. Interviews were audiotaped and transcribed verbatim. Analysis was thematic and comparisons made both within and across the interviews.

Results

Thirty practitioners were interviewed: 12 GPs, 10 practice nurses, four school nurses, and four health visitors. Participants varied in their views about whether primary care is an appropriate treatment setting for childhood obesity. However, all described factors that limited the extent to which they could intervene effectively: a lack of expertise, resources, and contact with primary school children; the causes of childhood obesity; and the need to work with parents. It was also apparent that very few participants had knowledge of the recent guidance.

\section{Conclusion}

Practitioners do not currently view primary care as an effective treatment setting for childhood obesity and it is unlikely that the guidance from the Department of Health and NICE will have a meaningful impact on their management of this condition.

Keywords

child health; obesity; primary health care; qualitative research.

\section{INTRODUCTION}

The prevalence of childhood obesity is increasing worldwide, posing a long-term threat to future health. ${ }^{1}$ Some advisory bodies view primary care as an appropriate setting in which to manage childhood obesity. ${ }^{2-4}$ In the UK in 2006 the Department of Health produced an obesity care pathway for children and young people to be used by primary care practitioners, ${ }^{5}$ and the National Institute for Health and Clinical Excellence (NICE) published guidance on the management and treatment of obesity. ${ }^{2}$ However, some clinicians argue that primary care is not a suitable setting for the treatment of obesity. ${ }^{6,7}$ In addition, uncertainty remains about how to treat childhood obesity effectively, ${ }^{8}$ and the Department of Health recognises that there is a need for further research in the primary care setting. ${ }^{9}$

Researchers have assessed primary care practitioners' views and experiences of treating childhood obesity. ${ }^{10-15}$ However, to date, only two studies have employed qualitative research methods that enabled practitioners' views and experiences to be explored in detail. ${ }^{14,15}$ In addition, the research undertaken so far in this area has been limited to assessing the views of GPs and practice nurses, and was carried out before the publication of the obesity care pathway and the NICE guidance.

KM Turner, BSc, MSc, PhD, lecturer in primary health care; C Salisbury, MD, FRCGP, professor of primary health care, Academic Unit of Primary Health Care, University of Bristol, Bristol. JPH Shield, MD, FRCPCH, professor of diabetes and metabolic endocrinology, Bristol Royal Hospital for Children and University of Bristol, Bristol.

Address for correspondence

Katrina M Turner, Academic Unit of Primary Health Care, University of Bristol, 25 Belgrave Road, Bristol BS8 2AA.

E-mail: katrina.turner@bristol.ac.uk

Submitted: 30 November 2008; Editor's response: 6 January 2009; final acceptance: 3 February 2009.

OBritish Journal of General Practice.

This article was originally online first on 26 Aug 2009. Cite this article as: Br J Gen Pract 2009; 59: 856-862. Advance online publication. DOI: 10.3399/bjgp09X472269 
Research using in-depth interviews with different primary care practitioners who might be involved in the treatment of childhood obesity could help identify the potential of this setting to carry out the requirements placed on it by the recent guidance. Therefore, this study held in-depth interviews with GPs, practice nurses, school nurses, and health visitors, in order to explore their views on primary care as a setting in which to treat childhood obesity.

\section{METHOD}

\section{Recruitment}

Seven general practices, based in Bristol, England, that served patient populations and varied in terms of their socioeconomic backgrounds and ethnicity were purposively sampled. GPs, practice nurses, and health visitors who were working within or attached to these practices were invited for interview. School nurses working in Bristol were contacted through a local school nurse lead. Practitioners volunteered for interview from five of the seven practices sampled (Table 1). Interviews were held with each practitioner who volunteered.

\section{Interviews}

The interviews were conducted by between June and October 2007. A topic guide was used to ensure key areas were explored during each interview (Box 1), while giving participants the opportunity to raise issues that were salient to them. Participants were informed that the researchers were particularly interested in their views about primary school children, as the Department of Health had set a target to halt the rise in obesity in children aged under 11 years, by $2010 .^{16}$

Thirty practitioners were interviewed. Data collection ended when saturation of key themes had been reached. Two participants were interviewed in their own homes, and the others at their place of work. The interviews lasted between 30 and 90 minutes. They were audiotaped and transcribed verbatim.

\section{Data analysis}

Each transcript was read and re-read to gain an overall understanding of the participants' views and experiences. This process was also used to identify emerging themes and to develop a coding frame. Transcripts were read and coded by different members of the research team, so that the analysis and coding frame could be refined through discussion.

Transcripts were imported into the software package NVivo to allow electronic coding and retrieval of data. Once all the transcripts had been coded, data were analysed using a framework approach. ${ }^{17}$ Using this method, tables were used to summarise what participants had said in relation to

\section{How this fits in}

In 2006 the Department of Health and the National Institute for Health and Clinical Excellence (NICE) issued guidance on the management of childhood obesity, for use by primary care clinicians. To date, few researchers have explored, in detail, practitioners' views and experiences of managing childhood obesity in primary care. This study shows that primary care practitioners are unaware of the guidance provided by NICE and the Department of Health; feel that they do not have the time, expertise, or resources with which to treat childhood obesity; and do not believe that any interventions they could deliver would be effective. Thus, the study suggests that it is unlikely that the recent guidance will have a meaningful impact on the primary care management of childhood obesity and that practitioners do not currently view primary care as a setting in which childhood obesity can be effectively treated.

specific issues, for example causes of childhood obesity, and then comparisons were made both within and across interviews to identify thematic patterns and deviant cases, and to identify similarities and differences between the professional groups.

To maintain confidentiality, quotations reproduced in this paper have been labelled with the participant's profession and interview number.

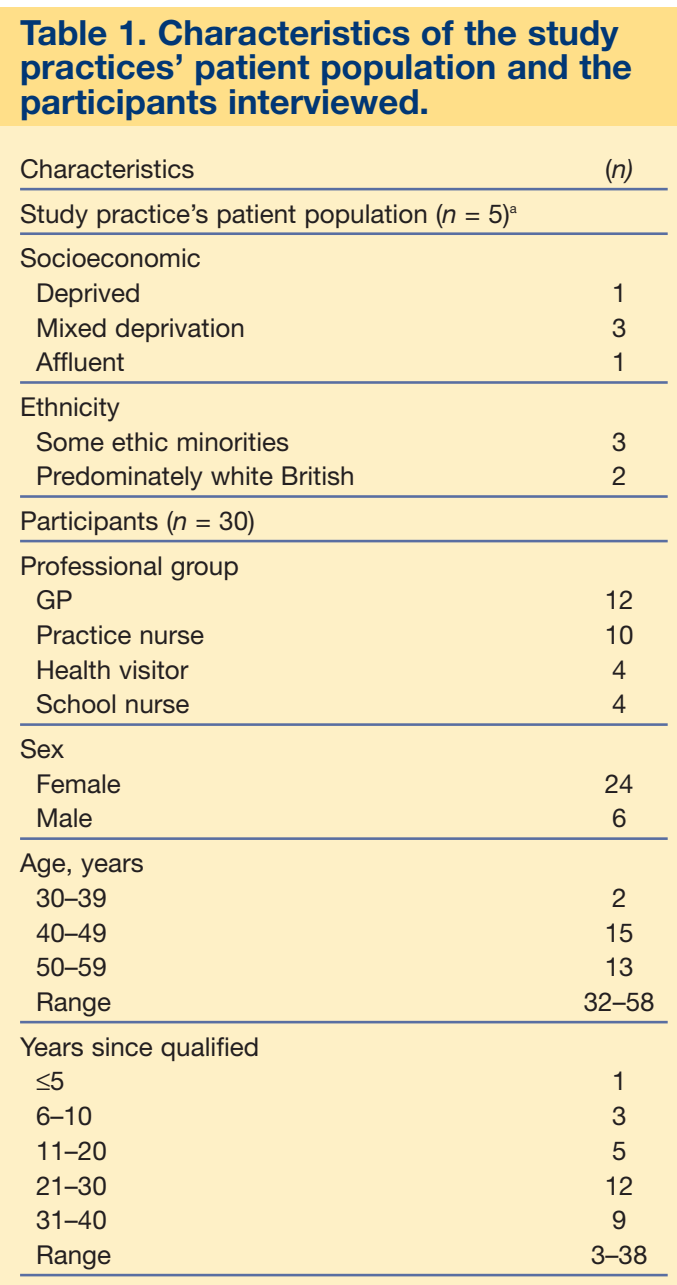

${ }^{a}$ As described by participants. 


\section{Box 1. Topic guide - domains of enquiry.}

- Causes and implications of childhood obesity

- Primary care as a treatment setting

Role of different primary care practitioners

- Ways to treat childhood obesity in primary care

- Practitioners' motivation and ability to treat childhood obesity

- Knowledge and use of the NICE guidance and the Department of Health's obesity care pathway

- Experiences of treating childhood obesity

- Experiences of working with obese children and their parents

\section{RESULTS}

Although all the participants commented that they were concerned about the current prevalence of childhood obesity, none of them had seen the Department of Health's obesity care pathway, and only two GPs and one practice nurse had looked at the NICE obesity guidance. It was also apparent that participants varied in their views about whether primary care was an appropriate setting in which to treat childhood obesity. There appeared to be no relationship between the participants' profession, age, sex, or length of time qualified, and whether or not they viewed primary care as a suitable treatment setting. There did appear to be some variation depending on patient population; GPs working in the most deprived areas emphasised that they should address childhood obesity because they had a 'community responsibility' (GP 8) and could 'see it happening' (GP 5).

\section{Primary care as a treatment setting}

Most participants stated that they thought primary care was an appropriate treatment setting. Primary care was reported to be suitable because it was community based, because GPs were known to families and could refer patients on to others for further support, and because obesity needed to be addressed before associated clinical complications developed:

'I think the aspects of it [primary care] that are particularly relevant are the fact that, you know, the continuity really, the fact that we know whole families, we know communities, we've got close links with people like health visitors and school nurses and that sort of thing.' (GP 10)

Interviewer (I): 'Do you think it's an appropriate setting or do you not?'

Participant (P): 'Primary care, yes.'

I: 'So why do you think it is?'
P: 'Because it needs to be tackled before the problems arise, otherwise you're dealing with a child who has clinical problems due to obesity, and we need to be preventing those, we need to be tackling the problem so that those problems don't arise.' (health visitor 2)

In addition, GPs, practice nurses, and health visitors were described by themselves and by others as being able to opportunistically mention a child's weight and provide advice, support, and follow-up. School nurses also commented that they could identify and work with obese children, and were described by the other participants as being, along with GPs, a first point of contact for parents of primary school children who were concerned about their child's weight. However, some GPs, a few practice nurses, and one school nurse felt primary care was not a suitable treatment setting. They commented that they and other primary care practitioners did not have the expertise or time to treat childhood obesity, and had no effective treatment to offer:

I haven't got the expertise in what to do and what not to do, I don't feel, and the time to do it all.' (practice nurse 1)

'We deal so much with child protection and child and adolescent mental health referring that we have very limited time for health promotion. Health promotion is just like the icing on the cake.' (school nurse 4)

'I don't have a way of them losing weight ... I'm motivated to treat things I think I might be able to make a difference with and I think my problem with this is I am not convinced I can make a difference.' (GP 2)

GPs also commented that obesity was a social rather than a medical problem, and implied that management of childhood obesity had been placed on them without careful thought:

I: 'Moving on to discuss the management of childhood obesity within primary care. What do you think of that? Do you view it as a setting that's appropriate?'

P: 'No. It's hopeless, it's hopeless ... If you turn it into a medical model, you treat individuals and it seems to me that isn't what the problem is at all. The problem is a big social problem ... to dump it on GPs and say, "here's a problem, you sort it out", is foolish and almost certain to fail.' (GP 7) 
In addition, GPs argued that it was financially imprudent to place treatment in primary care, and others commented that doing so would create the wrong mindset among patients:

'I think doctors, you're spending an awful lot of money on a problem by taking people who are probably not very well qualified to deal with it [childhood obesity] and who could be better used doing something else. I would try and medicalise it as little as possible ... put it into a framework that people are used to, which isn't as expensive.' (GP 11)

'It's not an illness that they've got and it's a life change that they need to make, so I think they don't need to see it as a come here, get fixed, and then go back to where they were.' (practice nurse 4)

Practice nurses described how they would feel uncomfortable focusing on an individual's weight in the absence of a related condition. Similarly, GPs explained that parents rarely came to discuss their child's weight and that they felt it would be inappropriate to broach the subject of a patient's weight unless it affected the problem the child was presenting with:

'I don't think if someone came to see me about a sore throat and they were overweight, I would necessarily feel that it's appropriate for me to say "oh, by the way, you're also overweight and we need to do something about it". But if someone came in with something that may be weight related, or have a weight component, I think it would be a fair enough point to say "have you thought about [your weight]?”. (GP 9)

Other reasons given for not broaching the subject were needing to prioritise the problem the patient was concerned about; feeling that they had no effective treatment or referral options to offer, and no incentives to encourage behavioural change, for example: exercise on prescription for children; being unsure about providing child-specific advice; worrying about upsetting the child or parent; and having no financial incentive to treat.

So a range of views were expressed about the suitability of primary care as a treatment setting. Yet, even those who had described primary care as an appropriate setting talked about having limited time, resources, and expertise to treat, and feeling that it was unlikely any treatment they provided would reduce a child's obesity. Thus, they were aware that there was a difference between what they thought was possible in theory and the reality of their situation:
'In theory, primary care is the right place [to treat] ... I don't know how we do it though.' (GP 3)

In addition, across the interviews there was a sense that, irrespective of a practitioner's own skills and motivation, management in primary care would have little impact. What practitioners could achieve was limited not only by their own skills and resources, but also by the level of contact they had with children, the causes of childhood obesity, and the need to work with parents.

\section{Limited contact with obese children}

None of the participants were in regular contact with obese children of primary school age. Health visitors explained that they now focused on children under the age of 5 years old and worked mainly with vulnerable families:

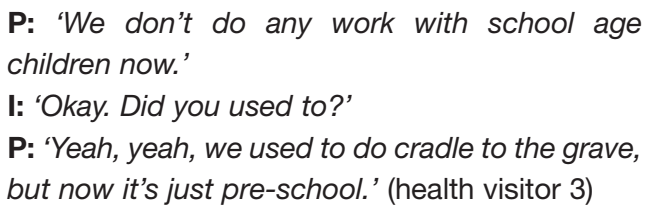

'We are more and more being directed to work with vulnerable families and families in need, and that's perfectly fair, but consequently, we're not monitoring health and development of the majority of children on as regular a basis as we used to do.' (health visitor 1)

School nurses stated that they could not focus on childhood obesity because they needed to prioritise child protection and child and adolescent mental health:

'I've got a child that's going into care ... l've got another child that's come to me because he's hearing voices and they're telling him to do bad things. Well, if you've got those sorts of things, you have to prioritise those ... childhood obesity becomes way down the list'. (school nurse 2)

Both GPs and practice nurses commented that they rarely saw primary school children in surgery, and GPs mentioned that they had limited appointment times that restricted what they could achieve:

'I've been at my practice about 4 years and there's one [obese child] ... Children consult quite frequently, don't they, but maybe it is pre-school age and teenagers more. Maybe it's an age group, primary school, that we don't see that much of.' (GP 10) 
'See them in baby clinic ... we don't really then see them until they're 13 when we send them a letter for the teen clinic.' (practice nurse 1)

I've got 10 minutes, or I probably haven't got 10 minutes because they have probably come with something else and we have dealt with that and there's now 2 minutes left ... you are not going to actually have any lasting impact because that's 2 minutes against 10 years of life.' (GP 3 )

Although GPs and practice nurses were able to offer follow-up appointments and had done so, most patients did not return. Also, as one GP highlighted, they only saw the small proportion of obese individuals who sought help from their GP:

'The problem is that all you're ever working with [is] volunteers, which is the nature of the system ... You sort of take off the top tip that ventures into your surgery, so that's not ever going to address an obesity epidemic.' (GP 11)

\section{Causes of childhood obesity}

Participants described the main causes of childhood obesity as an unhealthy diet and lack of physical activity. These in turn were related to factors that were beyond their influence, such as the availability of junk food, unsafe streets, and a lack of family cohesion:

I: 'What do you think are the causes of childhood obesity?'

P: 'The first thing that springs to mind is changes in the exercise provided. Also, diet and probably what's accessible, foods in supermarkets and pre-packed food, easy to cook foods ... Yeah, so lack of exercise, and around that, probably safety issues as well for the under age 11, so parents would, rather than have the child walk home from school, perhaps they would pick them up.' (practice nurse 5)

I think in the great majority of cases we are talking about social issues really. We are talking about kids not getting out and exercising and spending too much time in front of the television and parents probably not cooking terribly wellbalanced meals and so forth ... Some of this is just to do with society in general. Families are getting more disruptive. There's a general lack of cohesion within families ... Some of it is general: ready availability of non-nutritious food stuff; junk food; and people being too busy or too pressured, or what have you, to cook routine proper meals; and stuff to do with advertising as well.' (GP 3)

\section{Working with parents}

Each participant stressed that to address childhood obesity they would need to work with parents. However, participants who had mentioned to parents that their child was overweight, described how most parents had become defensive or denied there was a problem:

'How would you broach the subject when most parents can get quite nasty if you start? They think it's a blame, that you're blaming them.' (practice nurse 1)

'I think the hardest thing is getting the parents to acknowledge that it's a problem.' (health visitor 4)

'Some parents get really shirty about it. They won't accept it that their child has a weight problem.' (school nurse 4)

Parents were described as not making the link between eating junk food, physical inactivity, and obesity; as not having access to safe play areas; as struggling to take information on board; and as being unable to prepare healthy meals due to a lack of knowledge, money, or time. Participants commented that parents used food as a symbol of affection and thus felt uncomfortable denying their children food. Participants were also aware that parents might be struggling with other issues that meant obesity was not a priority:

'Around here, to eat well, eat good food, is expensive and people don't have the money and they have got lots of other problems and so that isn't high up on their list of priorities to be honest. Finding the money to pay the rent or whatever is more immediate than whether they are giving the best fresh fruit and vegetables that they and their children need.' (GP 5)

'There will be quite a lot of families who will be under a load of pressure, nothing to do with obesity, so you know, single parent families, people where both parents work, you know, parent situations where there's just very little time to do anything with your kid because you're just scraping through, people with drug addiction and mental health problems and so on ... there will be a subsection of the population where whatever you do isn't likely to work because they're already so under, dealing with their child's obesity is just going to be one of the things that really they could do without.' (GP 11)

Participants also mentioned that parents of obese 
children were usually overweight themselves. This was felt to hinder the extent to which they could manage their child's weight:

'She's got an eating problem that she can't identify herself, so she can't go home and educate her son.' (practice nurse 2)

'Very often parents of fat kids are fat themselves and they have got to somehow deal with that and make a change in themselves or accept that they are going to make some changes for their kids and not themselves, and that must be very difficult conceptually to do that.' (GP 3)

Having overweight parents was also described as 'normalising' obesity within the family and encouraging parents to believe genetic rather than lifestyle factors had led to their child's obesity. This in turn was reported as reducing their motivation to change their child's lifestyle.

\section{DISCUSSION}

\section{Summary of main findings}

Even practitioners who viewed primary care as an appropriate treatment setting for childhood obesity questioned the extent to which they could effectively treat this condition. Practitioners described a range of factors that prevented successful management. These included limited time; a lack of expertise, effective treatments, and referral options; limited contact with primary school children; the causes of childhood obesity; and the need to work with parents who are often unwilling or unable to address their child's weight. The study also showed that practitioners are unaware of the guidance provided by the Department of Health and NICE on the management of childhood obesity.

\section{Strengths and limitations of the study}

This study is the first to give insight into the views a range of practitioners hold towards the management of childhood obesity. The open nature of the interviews meant practitioners could detail their views and raise issues salient to them. Having a dataset detailing practitioners' views about primary care as a treatment setting, as well as their clinical experiences, enabled identification of a discrepancy between what some practitioners viewed as possible in theory, and what they knew to be possible in reality.

The generalisability of the study findings is limited by the fact that participants were recruited from five purposefully sampled practices, mainly women, mostly qualified for more than 20 years, and volunteers who might hold particular views about obesity management. Given that this was a small qualitative study, findings about relationships between participants' demographic characteristics and their views should be treated with caution. Interviewing practitioners at their place of work often restricted the amount of time available for interview and might have influenced the accounts given. As participants reported limited contact with obese children, their comments about the causes of childhood obesity and the extent to which parents are able to address their child's weight may have been based on commonly-held views or prejudices rather than clinical experience. In contrast, it is likely that their descriptions of, for example, the time constraints under which they work, would have been based on personal experience. Thus, when drawing conclusions from the present findings, thought should be given to the extent to which real experience underpinned the views expressed.

\section{Comparison with existing literature}

Previous studies have found GPs to be concerned about childhood obesity and viewing themselves as having some role to play in its management. ${ }^{12,14}$ The present study found evidence of this concern and view, not only among GPs but also among practice nurses, school nurses, and health visitors. In addition, researchers have identified GPs feeling professionally unprepared to manage childhood obesity, ${ }^{10,12}$ and perceiving their efforts as ineffective. ${ }^{14}$ This study showed that similar views are also held by other primary care professionals. In common with the present findings, other researchers have found low use of weight-management guidelines among GPs and practice nurses. ${ }^{18}$

A previous UK study also found GPs and practice nurses were discouraged from treating childhood obesity because of a lack of time and resources, and a concern about upsetting parents and children. ${ }^{14}$ Similar findings were reported by researchers in Australia who noted GPs being deterred from treating because of a lack of referral options and finding it easier to broach the subject of weight in the presence of associated health problems. ${ }^{15}$ They also described practitioners' awareness of the social causes of childhood obesity, how the behaviour and attitudes of parents could contribute to the problem, and that parents' own weight issues, denial, or defensiveness about their child's weight prevented treatment.

Neither of these studies mentioned limited contact with children as preventing practitioners from managing childhood obesity. This was a theme that was identified in the present study, and one that questions the view that primary care practitioners are well positioned to treat childhood obesity because they regularly see young children. ${ }^{19}$ Although 
consultations with children are a large proportion of primary care workload, most of these contacts are with children under 5 years of age and with adolescents. ${ }^{20}$

Primary care practitioners are reliant on parents cooperating in the management of their child's weight. Parents, however, may not recognise or accept that their child is overweight, ${ }^{21,22}$ or may not be concerned, ${ }^{23}$ or not wish to discuss the subject with a health professional..$^{21}$ This could explain why some of this study's participants talked about parents rarely seeking help about their child's weight and becoming defensive when they broached the subject.

This study focused on the management of childhood obesity and it is interesting to note that some of the themes identified have also been reported by researchers exploring practitioners' views of managing adult obesity. Researchers who interviewed GPs and practice nurses also found that practitioners viewed their efforts as ineffective, ${ }^{18,24}$ felt they had no effective treatment to offer, ${ }^{24}$ and felt more comfortable raising the subject of weight in the context of associated conditions. ${ }^{18}$ This suggests practitioners feel ill placed to undertake weight management, whether it involves adults or children.

\section{Implications for future clinical practice}

The findings of this study suggest the recent guidance provided by the Department of Health and NICE is unlikely to make a meaningful difference to the primary care management of childhood obesity. Practitioners are unaware of this guidance and do not have the time, expertise, or resources to treat childhood obesity. While additional training and funding might improve management within primary care, factors unrelated to practitioners' skills may continue to limit the effectiveness of any treatment provided. Thus, it would appear that primary care can only play a limited role in addressing the current obesity epidemic. For progress to be made, greater effort needs to be made to address the causes of childhood obesity and to develop effective interventions that can be delivered outside, as well as within, the primary care setting.

\section{Funding body}

The Royal College of General Practitioners Scientific Foundation Board (SFB/2006/03) and South West General Practice Trust funded the study

\section{Ethics committee}

Southmead Research Ethics Committee approved the study (MREC 06/Q2002/137)

\section{Competing interests}

The authors have stated that there are none

Acknowledgements

We thank the practice managers who assisted with recruitment, and the practitioners who took part in the study.

\section{Discuss this article}

Contribute and read comments about this article on the Discussion Forum: http://www.rcgp.org.uk/bjgp-discuss

\section{REFERENCES}

1. Reilly JJ, Methven E, McDowell ZC, et al. Health consequences of obesity. Arch Dis Child 2003; 88(9): 748-752.

2. National Institute for Health and Clinical Excellence. Obesity: guidance on the prevention, identification, assessment and management of overweight and obesity in adults and children. Clinical Guideline 43. London: NICE, 2006.

3. National Health and Medical Research Council. Clinical practice guidelines for the management of overweight and obesity in adults, children and adolescents - a guide for general practitioners. Canberra: NHMRC, 2003.

4. Scottish Intercollegiate Guidelines Network. Management of obesity in children and young people. A national clinical guideline. Edinburgh: SIGN, 2003.

5. Department of Health. Obesity care pathway and your weight, your health. London: Department of Health, 2006.

6. MacAuley D. Physical activity may be good for you but we are not the key players. Br J Gen Pract 2006; 56(532): 888.

7. Jarvis S. Obesity and the overworked GP. Br J Gen Pract 2006; 56(530): 654-655.

8. Summerbell CD, Ashton V, Campbell KJ, et al. Interventions for treating obesity in children. Cochrane Database Syst Rev 2003; 3: CD001872.

9. Department of Health. Consultation on obesity care pathway and resources for primary care. London: Department of Health, 2005. http://www.dh.gov.uk/en/Consultations/Closedconsultations/DH_4124 410 (accessed 28 Jul 2009).

10. Jelalian E, Boergers J, Sloan Alday C, Frank R. Survey of physician attitudes and practices related to pediatric obesity. Clin Pediatr 2003; 42(3): 235-245

11. Goldman RD, Modan-Moses D, Bujanover Y, et al. Physicians' attitude toward identification and management of childhood obesity in Israel. Clin Pediatr 2004; 43(8): 737-741.

12. Gerner B, McCallum Z, Sheehan J, et al. Are general practitioners equipped to detect child overweight/obesity? Survey and audit. $J$ Paediatr Child Health 2006; 42(4): 206-211.

13. Spurrier N, Magarey A, Wong C. Recognition and management of childhood overweight and obesity by clinicians. J Paediatr Child Health 2006; 42(7-8): 411-418.

14. Walker O, Strong M, Atchinson R, et al. A qualitative study of primary care clinicians' views of treating childhood obesity. BMC Fam Pract 2007; 8: 50-57.

15. King LA, Loss JHM, Wilkenfeld RL, et al. Australian GPs' perceptions about child and adolescent overweight and obesity. The Weight of Opinion Study. Br J Gen Pract 2007; 57(535): 124-129.

16. Department of Health. National standards, local action. Health and social care standards and planning framework, 2005-06-2007-08. London: Department of Health, 2004.

17. Ritchie J, Spencer L. Qualitative data analysis for applied policy research. In: Bryman A, Burgess RG (eds). Analysing qualitative data. London: Routledge, 1994; 173-194.

18. Mercer SW, Tessier S. A qualitative study of general practitioners' and practice nurses' attitudes to obesity management in primary care. Health Bull 2001; 59(4): 248-253.

19. Wake MA, McCallum Z. Secondary prevention of overweight in primary school children: what place for general practice? Med J Aust 2004; 181(2): 82-84.

20. The Information Centre for Health and Social Care. Trends in consultation rates in general practice 1995 to 2006: analysis of the QRESEARCH database. Leeds: The Information Centre for Health and Social Care, 2007.

21. Stewart L, Chapple J, Hughes AR, et al. Parents' journey through treatment for their child's obesity: a qualitative study. Arch Dis Child 2008; 93(8): 35-39.

22. Jeffery AN, Voss LD, Metcalf BS, et al. Parents' awareness of overweight in themselves and their children: cross-sectional study with a cohort (EarlyBird 21). BMJ 2005; 330(7481): 23-24.

23. Eckstein KC, Mikhall LM, Ariza AJ, et al. Parents' perceptions of their child's weight and health. Pediatrics 2006; 117(3): 681-690.

24. Epstein L, Ogden J. A qualitative study of GPs' views of treating obesity. Br J Gen Pract 2005; 55(519): 750-754. 